\title{
Processos de trabalho e de subjetivação de professores universitários de cursos de educação à distância
}

\author{
Maria Antonieta Mendes da Luz \\ Pontifícia Universidade Católica de Minas Gerais - Belo Horizonte - MG - Brasil \\ João Leite Ferreira Neto \\ Pontifícia Universidade Católica de Minas Gerais - Belo Horizonte - MG - Brasil
}

\begin{abstract}
Resumo
Este estudo teve por objetivo analisar a relação entre processos de trabalho e processos de subjetivação na atividade do ensino docente da educação à distância $(\mathrm{EaD})$. Optou-se por realizar uma pesquisa qualitativa e exploratória, que teve como procedimento o estudo de caso único e como instrumentos a observação, a pesquisa documental, o questionário e a entrevista semidirigida. Os resultados revelaram que os professores percebem as Tecnologias de Informação e Comunicação (TIC) como inerentes a todas as esferas de suas vidas, ocorrendo também, um acirramento do volume de trabalho e a necessidade de eles se disciplinarem. A organização do trabalho na EaD pressupõe uma nova forma de estruturar-se, em que existe aumento do controle, o que cerceia a autonomia docente; as relações socioprofissionais mediadas pelas TIC tornam o trabalho dos professores de EaD mais solitário mas, ao mesmo tempo, requerem uma equipe multidisciplinar para executar o trabalho docente.
\end{abstract}

Palavras-chave: Educação à distância; trabalho docente; subjetividade.

\section{The work processes and subjectivity of professors in distance education courses}

\begin{abstract}
This study aimed to analyze the relationship between work processes and subjective processes in the activity of teaching school of distance education (DE). We chose to perform a qualitative exploratory study, which had a policy of the single case study and as instruments observation, documentary research, questionnaire and semistructured interview. The results revealed that teachers realize the Information and Communication Technologies (ICT) as inherent in all spheres of their lives, occurring also an intensification of the workload and the need for them to discipline themselves. The organization of work in distance education requires a new way of structuring, in which there is increased control, which restricts the teaching autonomy; socio-professional relations mediated by ICTs make the work of distance education teachers lonelier but at the same time, require a multidisciplinary team to execute the teaching.
\end{abstract}

Keywords: Distance Education; teaching work; subjectivity.

\section{Procesos de trabajo y de subjetivación de profesores universitarios de cursos de educación a distancia}

\section{Resumen}

Este estudio tuvo por objetivo analizar la relación entre procesos de trabajo y procesos de subjetivación en la actividad de la enseñanza docente de la educación a distancia (EaD). Se optó por realizar una investigación cualitativa y exploratoria, que tuvo como procedimiento el estudio de caso único y como instrumentos la observación, la pesquisa documental, el cuestionario y la entrevista semi-dirigida. Los resultados revelaron que los profesores perciben las Tecnologías de Información y Comunicación (TIC) como inherentes a todas las esferas de sus vidas, ocurriendo también, un aumento del volumen de trabajo y la necesidad de ellos se disciplinar. La organización del trabajo en la EaD presupone una nueva forma de estructurarse, en que existe aumento del control, lo que frenarla autonomía docente; las relaciones socio-profesionales mediadas por las TIC vuelven el trabajo de los profesores de EaD más solitarios, pero, al mismo tiempo, requieren un equipo multidisciplinar para ejecutar el trabajo docente.

Palabras clave: Educación a distancia; trabajo docente; subjetividad. 


\section{Introdução}

Pretendeu-se neste estudo compreender a seguinte questão: Como os novos processos de trabalho intermediados pela tecnologia influenciam os processos de subjetivação dos professores da educação à distância (EaD)? Parte-se do pressuposto de que a organização do trabalho concorre para a produção de modos de subjetivação compatíveis com o novo perfil profissional almejado. Entretanto, isso não ocorre de modo determinístico, pois a normatização do trabalho faz com que os sujeitos criem estratégias e invenções em sua relação tanto com as tarefas quanto com os modos de subjetivação (Schwartz, 2011).

Esta pesquisa se justifica em sua relevância contemporânea, pois vivemos grandes transformações sociais, econômicas, tecnológicas e políticas, que impactam as relações de trabalho. Desloca-se das sociedades disciplinares, na qual a gestão organiza-se por meios de confinamento institucionalizados, para uma sociedade de controle, que com o suporte de tecnologias de informação e comunicação (TIC) realizam processos de dominação fora da materialidade do aparelho institucional, ao ar livre (Deleuze, 1992). No Brasil, convivemos concomitantemente com disciplinas e controles. Esses processos impactam a área da educação, que tem sido convocada a acompanhar as novas demandas do capitalismo, chamado "flexível", para atender às necessidades do mercado de trabalho de profissionais detentores de uma formação constante. As Instituições de Ensino Superior (IES) foram convocadas a atender esse novo contexto. Com o surgimento da telemática, o ensino à distância foi intensificado e ampliado de modo a atingir um número maior de pessoas. Estudar o impacto do trabalho da docência virtual poderá contribuir para a ampliação do campo do saber com relação a essa subjetividade em construção.

Os eixos de investigação desta pesquisa envolvem a inter-relação entre os novos processos de trabalho, intermediados pelas TIC, e os processos de subjetivação dos professores de EaD. Aborda-se a subjetivação como um processo resultante de fatores sociais, relacionais, políticos, ideológicos e tecnológicos, entre outros, que contribuem para a constituição da subjetividade. Focaliza-se a subjetividade em sua dimensão processual, visando entender como certos processos de subjetivação podem ser produzidos em face de certas condições dadas em contextos socioinstitucionais específicos. Segundo Rose (2001), a formação da subjetividade se dá a partir da "composição e da recomposição de forças, práticas e relações que tentam transformar - ou operam para transformar - os seres humanos em variadas formas de sujeito" (Rose, 2001, p.143).

Com base nessa concepção, a subjetividade é entendida mais como uma variável do que como uma constante, mais um processo (de subjetivação) do que um produto (sujeito estruturado), produzindo-se de modo diferente em diferentes contextos socioinstitucionais. Assim, entende-se subjetivação como um processo em permanente processualidade, que afeta e modifica a subjetividade, tornando-a continuamente variável.
Pode-se dizer, então, que o trabalho é um componente importante dos processos de subjetivação. Compreender como isso ocorre e que conexões são essas é o foco do nosso estudo e o que norteia esta pesquisa.

A abordagem teórica que sustenta esta pesquisa baseia-se predominantemente nas Clínicas do Trabalho, por meio da Psicodinâmica do Trabalho (Dejours) e em suas discussões sobre saúde e trabalho para a compreensão dos processos de trabalho; nos conceitos pós-estruturalistas de subjetividade (Foucault, Rose, Deleuze); e no diálogo com a literatura específica sobre EaD e as TIC.

A EaD surgiu como estratégia para atenderàs necessidades do novo capitalismo, cujas estratégias de produção (menores quantidades e maior variedade), juntamente com a flexibilidade diante dos novos mercados e produtos, a globalização, a competição e as novas tecnologias, fazem com que as instituições educacionais se deparem com novas demandas de formação de indivíduos multicompetentes e que necessitam de um processo de aprendizagem constante. Para atender a esse novo contexto, passam a incorporar novas tecnologias, que possibilitam atender a umpúblicoespecíficode alunos e a oferecer cursos e disciplinas variadas. Surgem, então, novos modos de trabalho, para os quais os professores nele inseridos passam a utilizar novas formas de transmissão do conhecimento, de confecção de material didático e de alocação de tempo de aula e de espaço físico. Esse espaço e esse tempo deslocaram-se de uma materialidade, de um local fixo e determinado, para novas maneiras de utilizá-lo, em que se misturam o público e o privado, o social e o familiar, o trabalho e o lazer.

A instituição pesquisada é uma universidade privada confessional que possui uma estrutura multicampi composta por vários prédios, que abrigam laboratórios, bibliotecas, museu, canal de TV, oficina de teatro, ensino à distância, salas multimídia, teatros, auditórios, hospitais veterinários, clínicas de fisioterapia, odontologia e psicologia, além de outros equipamentos dotados de modernos recursos tecnológicos e pedagógicos.

A instituição oferece três cursos exclusivamente à distância: Administração, Ciências Contábeis e Gestão Pública, sendo que este último está sendo extinto por ter sido criado para atender a uma demanda específica do Estado, que deixou de existir. Em dezembro de 2013, essa instituição possuía 150 alunos do curso de graduação em Administração EaD, 350 de Ciências Contábeis e 3.000 alunos matriculados em todos os outros cursos presenciais que possuem algumas disciplinas à distância. Nesses cursos, até $20 \%$ da carga horária das disciplinas podem ser cumpridas virtualmente. O objetivo é oferecer projetos e cursos de educação à distância destinados a alunos tanto do Brasil como do exterior, utilizando, principalmente, as novas tecnologias de informação e da comunicação - mais especificamente, a internet.

O aluno conta também com acompanhamento de professores e tutores e o suporte das equipes acadêmica e tecnológica. A partir da proposta educacional e do projeto didático-pedagógico de cada curso, são selecionadas as 
tecnologias a serem utilizadas, adaptando-se o conteúdo e as atividades à linguagem própria de mídias variadas (vídeos, teleconferências, internet, material didático do curso na internet e DVD).

\section{Método}

Optou-se por realizar uma pesquisa qualitativa e exploratória, tendo como método o estudo de caso único e como instrumentos a observação, a pesquisa documental, o questionário e a entrevista semidirigida.Como o número de respostas ao questionário foi pequeno e, consequentemente, não foi representativo - ou seja, 12 em um público-alvo de 50 professores -, optou-se por não considerar todas as questões objetivas, com exceção daquelas que acrescentaram dados importantes às categorias de análise e utilizar principalmente as questões abertas, por meio de análise de conteúdo.

Os questionários foram enviados pelos coordenadores dos cursos de Administração e Contábeis à Distância, com as explicações da pesquisadora e a solicitação para que retornassem para o e-mail dela. As entrevistas foram marcadas com aqueles que se mostraram disponíveis pelo e-mail a participar, além de contatos pessoais nas salas dos professores. Foram realizadas em salas próprias da instituição pesquisada ou nos bancos dos jardins.
O critério de inclusão foi buscar professores que exerciam ambas as modalidades de ensino (Presencial e EaD) que pertenciam a um dos dois cursos em funcionamento pleno, Administração ou Ciências Contábeis e que se mostraram disponíveis para contribuir com a pesquisa. Um ex-professor de EaD e um da pós-graduação lato sensuem EaD demonstraram interesse em participar e por essa razão foram incluídos. Portanto, a amostra foi intencional, não probabilística. Participaram da pesquisa 15 professores de $\mathrm{EaD}$, que lecionam também na modalidade presencial e dois gestores do sistema virtual.

Não foram pesquisados os tutores, pois pertencem à categoria técnico-administrativa, sendo responsáveis pelo ambiente virtual e de apoio ao professor e ao aluno, sem exercerem atividade de ensino, além de não serem eles o foco deste trabalho.

Dos nove professores entrevistados, seis responderam também ao questionário. Dos 12 que responderam, seis não foram entrevistados. Assim, foram analisadas as respostas de 15 participantes, contemplando as questões abertas dos questionários, algumas poucas fechadas e as entrevistas, além das duas entrevistas com os gestores.

O número de professores dos cursos pesquisados no ano de 2012 era de 17 professores do curso de Administração e 34 do curso de Ciências Contábeis.Os participantes que responderam às entrevistas e aos questionários foram assim denominados, conforme a Tabela 1:

Tabela 1 - Participantes.

\begin{tabular}{lll}
\hline Participante & Instrumento de coleta de dados & Sexo \\
\hline E1 & Entrevista & Feminino \\
\hline EQ2 & Entrevista e Questionário & Masculino \\
\hline EQ3 & Entrevista e Questionário & Masculino \\
\hline EQ4 & Entrevista e Questionário & Feminino \\
\hline EQ5 & Entrevista e Questionário & Masculino \\
\hline E6 & Entrevista & Feminino \\
\hline EQ7 & Entrevista e Questionário & Masculino \\
\hline EQ8 & Entrevista e Questionário & Masculino \\
\hline E9 & Entrevista & Feminino \\
\hline Q10 & Questionário & Masculino \\
\hline Q11 & Questionário & Masculino \\
\hline Q12 & Questionário & Masculino \\
\hline Q13 & Questionário & Masculino \\
\hline Q14 & Questionário & Feminino \\
\hline Q15 & Questionário & Feminino \\
\hline & & \\
\hline
\end{tabular}

Nota. E - entrevistado; Q - questionário; EQ: entrevistado e questionário, seguido pelos números correspondentes. 
As características da amostra foram bem variadas: um participante possui titulação de doutor, sete são mestres, cinco são especialistas e dois possuem somente curso de graduação. Quanto ao estado civil, sete são casados, três são solteiros; quatro são divorciados e um é viúvo. O participante mais novo tem 31 anos de idade e o mais velho tem 75 anos. Como professor presencial, o tempo de trabalho na Instituição variou entre 7 anos e 39 anos; como professor de EaD, de 6 meses a 10 anos.

Os dados foram analisados por meio da análise de conteúdo. As categorias foram definidas a priori, mediante referências teóricas, e a posteriori, a partir dos dados produzidos, e são as seguintes: organização do trabalho; relações socioprofissionais; influência das tecnologias da informação e comunicação no trabalho e na qualidade de vida dos professores de EaD; e reconhecimento, realização e expectativas profissionais.

\section{Resultados e Discussão}

\section{Organização do trabalho}

Para Dejours, Abdoucheli \& Jayet (2007), a organização do trabalho pode ser compreendida como a forma de definir, dividir e distribuir as tarefas, de fazer prescrições e a fiscalização das operações, de fazer o controle do trabalho, definir a ordem, a direção e a hierarquia. Nesta categoria abordam-se, a partir da análise do conteúdo das falas dos participantes, o conteúdo, a estruturação, o controle e a autonomia do trabalho, as mudanças observadas nesses quesitos e a comparação entre o ensino presencial e o ensino à distância.

A organização do trabalho na $\mathrm{EaD}$ é bem diferente daquela na modalidade presencial. É importante salientar que não há como deslocar a estruturação, os controles e a veiculação dos conteúdos da modalidade presencial para a virtual. A autonomia muda, pois mesmo sendo mencionada pelos gestores e por alguns professores como existente na EaD, ela é cerceada pelos controles propiciados pelo sistema. Os processos de subjetivação dos professores estão submetidos a um sistema em que é exercido controle sobre todo o seu trabalho. Torna-se necessário ser planejador e inovador, assim como deixar de ser detentor do conhecimento para ser mediador e direcionador das melhores fontes de pesquisa e saber aglutinar os diversos recursos disponíveis na web e outros. A subjetivação do professor ocorre modulada pelo controle e a autonomia é relativa. $\mathrm{O}$ papel do professor muda, deixando de ser solitário no planejamento das aulas para fazer parte de uma equipe virtual multidisciplinar. Deixa de ser dialógico, de propiciar a transferência do aluno e de servir como modelo e incentivador do desejo de conhecimento para um "fazer" solitário, mediado pelo computador, fluido, desterritorializado, na medida em que atende a alunos em várias regiões geográficas distantes entre si. Isso constitui um paradoxo na formação do aluno e no papel do professor, pois a sala de aula representa mais do que simplesmente a transmissão do conhecimento, o que a EaD possibilita com certa facilidade, mas além disso, a possibilidade de discutir conceitos, críticas, reformulações de questões, ampliação da visão, abstração. Por sua vez, o professor também deixa de ter a possibilidade do diálogo simultâneo com o aluno, de ver a expressão dele, de ouvir suas dúvidas e questionamentos.

Há unanimidade na afirmação dos participantes ao relatarem que não percebem diferença entre os conteúdos lecionados numa modalidade e em outra. "O conteúdo é praticamente o mesmo. Não tem tanta diferença. Não tem praticamente quase diferença. Conteúdo é conteúdo. Aí cabe ao professor exatamente preparar o material adequado" (EQ2).

Confirma essa afirmativa também EQ3:

O conteúdo é o mesmo. A diferença é que no presencial você acompanha o ritmo da turma. A turma que tem mais dificuldade você fica mais tempo. Já no virtual, não, o ritmo é aquele definido pelo cronograma e solto no primeiro dia. $E$, aí, o aluno tem que correr atrás, tem que entregar os trabalhos nos prazos e não tem muita flexibilidade (EQ 3).

No virtual, o cronograma dita o ritmo e não a dificuldade com o conteúdo expresso pelos alunos. Não é possível fazer adaptações ao ritmo da aprendizagem. Ou seja, não há flexibilidade no sistema. Percebe-se outro paradoxo nessa situação, pois a EaD possibilita flexibilidade para o aluno fazer seus horários de estudo e atividades, mas ao mesmo tempo é um sistema enrijecido. Perguntamo-nos: o tecnológico suplanta o pedagógico? Parece que sim, o que pode contribuir para uma redução da qualidade do ensino.

As afirmativas dos entrevistados apontam algo em comum com relação à autonomia. Ela parece existir no que se refere ao conteúdo e ao horário de trabalho, porém há um controle maior com relação ao cronograma, ao número de acesso ao sistema e à forma do conteúdo inserido no ambiente virtual. Alguns professores consideram positivo o controle, o acompanhamento e o retorno sobre como veiculam o conteúdo no ambiente virtual; outros, nem tanto.

Com relação ao controle e à autonomia EQ3 demonstra lidar bem com estes quesitos, por acessar com frequência o sistema e sentir que possui liberdade na execução do seu trabalho:

Os dois [controle e autonomia] a gente tem total liberdade. Hoje a instituição instalou um novo programa, que já faz o controle de qual professor acessou, quanto tempo, o tutor. Mas, como eu já tenho costume de entrar várias vezes ao dia, todos os dias, pra mim não afetou nada. Acredito que aquele professor que entre muito pouco e tutor que praticamente não acessa vai ficar visível isso, mas não é o meu caso. Então, pra mim, continua o mesmo nos dois casos.

É possível associar as afirmativas expressas pelos professores com a sociedade disciplinar, conceituada por Foucault, e a sociedade de controle, explorada por Deleuze 
(1992). A aula presencial aproximar-se-ia mais da sociedade disciplinar, em seu manejo espacial do tempo e a EaD da sociedade de controle, na qual o controle é realizado pelas tecnologias de informação e comunicação, e não mais pelos espaços de confinamento da disciplina.

Percebe-se pela narrativa desses professores uma inserção na sociedade de controle, em que não se controlam o corpo físico e o tempo em determinado espaço, mas as ações realizadas, o número de acesso ao sistema, a forma de se comunicarem com os alunos, os conteúdos ministrados e disponibilizados.

Dejours (2011a) alerta sobre o excesso de prescrição das atividades, pois o trabalho não está reduzido às relações sociais nem ao salário e às relações de poder. $\mathrm{O}$ que está prescrito nunca consegue atender a toda a necessidade do trabalho. As máquinas substituem as padronizações, mas a inteligência humana e a criatividade são únicas e impossíveis de serem normatizadas. O trabalho é também a criação do novo, do inédito. Assim, precisa da iniciativa, da autonomia, da engenhosidade.

O trabalho do professor, seja na modalidade da EaD ou na presencial, precisa da autonomia para deixar vir à tona a mobilização subjetiva e, junto com ela, a inteligência, a capacidade de realização, que são mediadas pelo trabalho real. Para o trabalho ter sentido, precisa do reconhecimento, premiando suas expectativas com respeito a sua realização pessoal.

Para Dejours (1992), todo trabalho é fonte de satisfação sublimatória, sendo mais frequente em profissões liberais, de artesãos e de altos dirigentes, devido à possibilidade de modificarem a organização do seu próprio trabalho, de acordo com seu ritmo biológico, endócrino e psicoafetivo. Pressupõe-se que na atividade de professor presencial também é possível esse arranjo, porém na EaD há maior controle e registro, maior divisão das atividades, apesar da flexibilidade de horário e tempo de trabalho. Mas também não se pode afirmar que não é possível a sublimação, pois desde que ele se identifique com as atividades e consiga visualizar um significado para o seu trabalho, provavelmente poderá se sentir feliz.

\section{Relações socioprofissionais}

Consideram-se componentes da relação de trabalho as relações grupais formais ou informais que se estabelecem na organização em decorrência dos modos de gestão do trabalho, da comunicação e da interação profissional. Para Dejours (1992, p. 75), relações de trabalho são todos os laços humanos criados pela organização do trabalho: "relações com a hierarquia, com as chefias, com a supervisão, com os outros trabalhadores - e que são às vezes desagradáveis, até insuportáveis".

As relações socioprofissionais na $\mathrm{EaD}$ sofrem grande mudança por tratar-se de um trabalho mais solitário do que o presencial, mas, ao mesmo tempo multidisciplinar, pois o professor depende de uma equipe para conseguir colocar uma disciplina no ar. Ele deixa de atuar numa dimensão física, em que o costume de pertencer a um local físico, com os rituais inerentes à sala de aula, e os encontros com os colegas aconteciam, para atuar em sua própria casa. Há novas formas de se lidar com o tempo e o espaço. Os professores estão aprendendo a atuar nessa nova maneira de trabalhar, delimitando o público e o privado, as relações profissionais e pessoais e o tempo dedicado ao trabalho e ao lazer. A subjetivação ocorre nas novas maneiras de se relacionar com os alunos, com colegas, independentemente da localização geográfica, e com as equipes de trabalho virtuais. $O$ professor não precisa preocupar-se em dar um show de aula, como um ator ao apresentar uma peça, mas em transmitir o conhecimento de maneira organizada e clara, utilizando a escrita, e não a verbalização. Os processos de subjetivação passam a depender de novas formas de se estabelecer os laços socioprofissionais com os colegas, com os alunos, com a equipe de suporte e com os gestores. Faz-se necessário construir outros espaços de encontros sociais, pois o trabalho virtual não os possibilita. Como disse o professor EQ4: "A EaD distancia você de tudo". Na instituição pesquisada os professores pertencem também à modalidade presencial, portanto, esta situação ainda não se configura como um problema maior. Passa a existir a compensação por meio dos contatos exercidos entre os pares e com os alunos no ambiente das aulas presenciais.

\begin{abstract}
A relação professor-instituição eu não vejo muita diferença, a não ser, como eu disse, uma nova chefia, mas com relação aos alunos, sem dúvida, há um distanciamento maior. $\mathrm{Na}$ sala de aula, você acaba construindo relações, muitas vezes, até mesmo de amizade, que são mantidas depois do termino do semestre. Virtualmente, isso é muito raro de acontecer (EQ 5).
\end{abstract}

A frieza nas relações também é percebida como uma nova maneira de ver o outro. Entretanto, outra entrevistada, EQ4, considera que se deve aprender a construir essa nova maneira de relacionar-se, citando como exemplo as redes sociais. E9 afirma que na relação com os alunos há um pouco de angústia, por não se ver a expressão deles. Com o tempo, a forma de conhecê-los é pelo que escrevem, e daí vai construindo a história de cada um. Porém, se o aluno não se expressar por escrito, não se consegue conhecê-lo.

Bom, a relação com os alunos a gente aprende, mas ela é
bem diferente, porque você não está enxergando o aluno,
você não o conhece. Com o tempo, você vai conhecendo ele
pela forma de escrever, pela forma de se expressar. Você
vai construindo uma história de cada um. Mas é diferente
do presencial, que você enxerga o rostinho deles, você vê
a angústia. Aqui, se o aluno não se expressar, você não
descobre. Então, você fica o tempo inteiro buscando aquela
expressão (E9).

Continua a professora E9: "Talvez para um aluno recém-saído do ensino médio a $E a D$ não seja tão bom, pois 
ele precisa aprender com exemplos de outras pessoas, com modelos". A maioria dos alunos que a universidade recebe é mais velha, está inserida no mercado de trabalho e possui outro curso de graduação. A forma como se relacionam entre si se dá pelo ambiente virtual, por exemplo, via facebook. Com a instituição, eles também se relacionam por meio do ambiente virtual.

Aprender a trabalhar numa outra dimensão de espaço e a reconstruir as relações por meio do virtual foi a afirmativa da EQ4:

Ela modificou a estrutura do processo, com certeza, o espaço... [interrupção] $O$ espaço, por exemplo, aquele contato em sala de aula de você ver o aluno, você perceber a reação do aluno. Isso na EAD é diferente, é totalmente frio. Você pode construir isso? Pode. Como você constrói isso nas redes sociais, você pode construir isso nas relações com os alunos.

Percebe-se um sentimento de perda de identidade e de pertencimento a um local físico, às pessoas, a uma história construída junto. Todavia, a entrevistada acredita que isso pode ser resgatado por meio das novas formas de se relacionar utilizando-se os recursos da internet. As redes sociais são um exemplo da tentativa de se resgatar essas relações.

Com a EaD corre-se o risco de ver os espaços coletivos de troca de experiências e que contribuem para amenizar o sofrimento desaparecerem, conforme afirma E6: "o virtual acaba com a história do ensino. Não vai ter Diretório Acadêmico, movimento dos alunos, relação dos professores com a associação representativa, discussões sobre questões pedagógicas".A ausência de espaços coletivos desarticula a mobilização de uma agenda de mudanças produzida pelos docentes, mantendo-os em certo isolamento estratégico. EQ8 corrobora esse pensamento ao afirmar que considera que houve perda nas relações entre os professores, que inexiste na EaD, diferentemente do presencial: "A relação com os colegas eu penso que no presencial é melhor. No ensino a distância a gente não tem muita interação".

Para Dejours (2011b, p. 435), "a dinâmica do trabalho opera em um campo no qual atuam o sujeito (a pessoa no trabalho), o real (em outros termos, a organização prescrita que lança os parâmetros a partir dos quais se trabalha) e o outro". Ou seja, existe a necessidade de um espaço de diálogo, de trocas, mesmo que o perfeito entendimento entre as pessoas seja uma ficção. Diante destas constatações, a $\mathrm{EaD}$ deve ter um espaço coletivo em que os professores possam trazer suas dúvidas, sugestões e angústias, bem como espaços de congraçamento (coquetéis, festas e outros), como oportunidades de troca de objetivos, interesses e valores, independentes das relações hierárquicas. Mas, pelo contrário, percebe-se na nova forma de organização do trabalho, mesmo no ensino presencial, a diminuição desses espaços de discussão coletivos, em função da falta de tempo, do acirramento da competição por espaços profissionais, do atendimento a resultados que premiem as avaliações a que estão sujeitas às instituições de ensino e diversos outros.

Para Ponte (2000), a relação professor-aluno pode sofrer grandes alterações devido ao uso das TIC, por exemplo, na resolução de um problema, na realização de um projeto, na pesquisa e na interpretação da informação recolhida. O professor deve compreender em profundidade as necessidades e as ideias do aluno, para conseguir responder às suas dúvidas e questões. O papel do professor junto ao aluno passa a serde parceiro na construção do conhecimento.

Com relação aos colegas, Ponte (2000) ressalta que o professorpode usufruirmais possibilidades de ser colaborativo com os colegas em virtude das facilidades proporcionadas pela internet. Consegue enviar e receber mensagens e documentos em tempo real, criar páginas coletivas, interagir com professores de outras escolas e de organizações profissionais e acompanhar o que se passa em outros países em sua área de atuação, além de outras possibilidades. Contudo, essa não foi a percepção da maioria dos entrevistados.

Para Chanlat (2011), o desafio que se coloca aos gestores atualmente não é controlar o tempo físico, mas produzir em um espaço de tempo fragmentado e estabelecer os laços sociais. A cooperação e a confiança nos colegas e nos gestores ocorrem a partir do tempo e da proximidade social. Se não há essa proximidade, como construir relações de confiança quando as relações são somente virtuais? Ou seja, é necessário que os gestores propiciem locais comuns para reuniões e discussão dos problemas dos trabalhos, para permitir a construção de espaços de confiança, de relações sociais e de solução de problemas oriundos do trabalho. No caso da instituição pesquisada, os encontros são feitos semestralmente, nas reuniões de planejamento, mas não há um espaço delimitado para a discussão de aspectos subjetivos ao trabalho.

\section{A influência das Tecnologias de Informação e Comunicação no trabalho e na qualidade de vida dos professores de EaD}

Abordam-se aqui como integrantes desta categoria a relação entre as TIC, o trabalho e a qualidade de vida dos professores. Segundo Belloni (2003, p.58), as TIC oferecem possibilidades inéditas de interação midiatizadas entre professor/aluno e estudante/estudante, além de interatividade com materiais de boa qualidade e grande variedade. Para a autora, as novas técnicas de interação por meio das redes telemáticas, como e-mail, grupos de discussão, webe outros, possibilitam "combinar a flexibilidade da interação humana ... com a independência no tempo e no espaço».

Pode-se conceituar qualidade de vida do ponto de vista das pessoas como: «percepção de bem-estar, a partir das necessidades individuais, ambiente social e econômico e expectativa de vida» (França, 2007, p. 167). Para essa autora, qualidade de vida é uma junção da saúde e ergonomia, associadas à ética da condição humana. Deve-se identificar, 
eliminar, neutralizar e controlar os riscos ocupacionais no ambiente físico e ter padrões de relações de trabalho, carga física e mental requerida para cada atividade, implicações políticas e ideológicas, estilos de liderança e do poder formal e informal delineados. Além disso, o trabalho deve ser significativo.

Com relação às TIC, sua intermediação com o trabaIho não foi considerada um dificultador pelos professores, pois atualmente elas estão presentes em todas as esferas da vida das pessoas. A afinidade com a tecnologia, porém, possibilita melhor desempenho do professor, pois facilita a interatividade na utilização da web para aprimoramento dos recursos das aulas. Os processos de subjetivação ocorrem em um ambiente de mudança constante, de "aprender" e "desaprender" o tempo todo, de utilizar o computador como um interceptador do olhar do outro, de atuar em um espaço e em um tempo submetidos ao virtual, em que as dimensões são mensuradas de outra forma.

O sistema utilizado, chamado Moodle, foi considerado bom e atende àquilo que precisam. A tecnologia atende ao conteúdo do trabalho deles e possibilita-Ihes trabalhar em sua própria casa, sendo eles mesmos responsáveis pelos seus próprios equipamentos, tanto dos computadores domésticos quanto dos note e netbooks ou outros dispositivos. Isso representa uma mudança de responsabilização pelo fornecimento de equipamentos de trabalho, pois na $\mathrm{EaD}$ a instituição deixa de ser responsável por fornecê-los a seus professores e de cuidar da manutenção deles.

A flexibilidade propiciada pelo horário e pelo espaço é encarada positivamente pela maioria deles, mas alguns assinalam que isso é aparente, pois houve aumento da carga de atividades, o que pode significar uma precarização das condições de trabalho.

EQ5 não sente estranhamento com as novas tecnologias: "A questão de novas tecnologias é inevitável, sem dúvida, e a gente tem que tentar se ajustar. Eu não sou um especialista em tecnologia, mas consigo me virar numa boa”. E6 percebe que a EaD contribui para o empobrecimento da formação dos alunos.

Ela facilitaria enquanto fosse ordenadora desse processo. Ela vai ordenar no sentido de que vai exigir que o professor tenha o curso dele bem programado, as atividades. Quer dizer, pedagogicamente, ele vai exigir uma melhor qualificação pedagógica do professor. Mas ele também vai amordaçar, porque com esse processo a distância a avaliação nunca vai ser dialógica...

Essa afirmativa remete à questão da transferência que ocorre entre professor e aluno como um fator importante para que aconteça a aprendizagem, no conceito psicanalítico, bem como à questão de ser o professor um incentivador do aparecimento do desejo de aprender do aluno. Na EaD, na forma como se usa a tecnologia atualmente, isso não ocorre.

EQ3 menciona a evolução da tecnologia usada na EaD como uma forma de contribuir para o acompanhamento do aprendizado do aluno. E que essa evolução também deve atingir a habilidade do docente de operar pedagogicamente com a tecnologia:

Acho que a própria tecnologia, à medida que vai evoluindo, vai abrindo alternativas para, no futuro ter uma interação maior [com o aluno]. O importante é isso, você perceber que se o aluno está tento uma dificuldade, mesmo que ele não escreva, você pode pegar aquela dificuldade e acessar esses alunos. Hoje, isso não tem sido feito porque não tem o que fazer.

Percebe-se, pela maioria das afirmativas dos professores, a necessidade de disciplinarem seu tempo para conseguirem conciliar atividades pessoais com atividades profissionais. Os professores que melhor delimitam esse tempo são aqueles que demonstram menos angústia diante dessa divisão tênue entre as esferas profissional e pessoal, já que o tempo e o espaço se misturam nessa nova modalidade. Afirma EQ7: "É como eu levo minha vida: é trabalho de segunda a sexta, mas final de semana eu nem passo perto de tecnologia... numa disciplina de 30 horas você pode saber que você vai trabalhar em torno de 60/80 horas".

EQ2 enfatiza que a EaD é uma atividade para ser desenvolvida em casa e que possui mais tempo para isso, já que não precisa deslocar-se e se trabalha mais rápido. Afirma ele:

A EaD é em casa. E vamos colocar o seguinte: eu tenho mais tempo. A EaD me possibilitou mais tempo para realizar outras coisas profissionais que eu quero fazer. Talvez por eu ser organizado, eu mato muito rápido, corrijo minhas provas muito rápido, corrijo trabalho muito rápido.

Os professores de EaD estão diante de uma nova maneira de trabalhar, de delimitar seu tempo, de definir o limite entre o espaço social, pessoal e profissional. Tanto o professor como a instituição e a área de Medicina e Segurança do Trabalho necessitam conhecer melhor as consequências do trabalho na vida social, psíquica e na saúde do trabalhador, no intuito de prevenir possíveis problemas decorrentes do trabalho virtual.

$\mathrm{Na}$ modalidade da EaD, passa a existir a falta do contato visual e verbal, sendo esta uma característica do ambiente virtual e do mundo moderno. As relações profissionais, educacionais, sociais e familiares, muitas vezes ocorrem por meio da utilização da telemática. Segundo Barros e Gil (2008), vive-se em um mundo rodeado de imagens virtuais, em que sua emissão, absorção, criação e destruição acontecem em um tempo veloz. O tempo é estruturado, organizado e vivenciado de acordo com a imaginação, decorrente da percepção de cada pessoa e a realidade é constituída de tempos experimentados, falados e sentidos (Barros \& Gil, 2008).

Atualmente, são grandes as diferenças existentes entre a EaD e o ensino Presencial. A EaD pressupõe aprender a "ensinar" e a "aprender" em um ambiente em que os 
espaços e tempos são diferentes, a informação é muito mais veloz, e o conhecimento está disponível a um toque do mouse. Exige-se um professor mediador do conhecimento, assim como um aluno autônomo, para que se consiga tirar o melhor proveito da nova forma de ensinar e de aprender. Mas podemos supor que certos aspectos do EaD impactam também o ensino presencial e com o tempo, tais diferenças irão se reduzir, pois se o espaço de discussão e de contato coletivo vier a se restringir com o aumento das disciplinas virtuais, diminuirá a possibilidade dos momentos das aulas se constituírem além da simples transmissão de conhecimento. Questiona-se então: Como ficam as relações entre alunos e professores, o diálogo entre ambos e as discussões, que são tão enriquecedores para a constituição da aprendizagem e da formação do aluno?

O impacto maior das mudanças é com relação ao trabalho realizado em um novo tempo e em um novo espaço. Entretanto, essa aparente liberdade pode trazer como consequência uma insalubre invasão do trabalho sobre as relações familiares, o lazer e o descanso. A divisão convencional de tempo e de espaço de trabalho e fora do trabalho garante de modo mais evidente o lazer e o descanso. Em face das novas condições, esses aspectos precisarão receber nova atenção, para se evitar a situação de um trabalho sem fim, permanentemente conectado. O professor EQ5, que possui uma carga de trabalho elevada devido à junção de atividades em uma instituição pública e na Universidade como docente do ensino presencial e virtual, assim se manifestou:

\footnotetext{
... às vezes, vamos abandonando um pouco a família. Às vezes, cria irritação: "Pai, sai do computador!" A esposa reclamando: "Não. A gente não tinha combinado que ia passear agora?". Aí, eu falei: "Olha, eu tenho um punhado de dúvidas que tem que ser respondidas antes da prova”. Os alunos todos deixam pra postar as dúvidas 24 horas antes da prova, apesar de ter vários comunicados pedindo que não deixassem pra última hora.
}

Esse novo tempo e esse novo espaço também modificaram os hábitos das pessoas com relação ao exercício de suas atividades profissionais em determinado local, em determinada instituição, que tinha uma história, uma arquitetura. Para Mill \& Fidalgo (2009), a relação espaço-temporal convencional constituía parte importante da definição da identificação e da cultura de uma instituição acadêmica, fazendo parte da constituição dos grupos os lugares predeterminados da sala de aula, das instalações físicas comuns, dos laboratórios e dos espaços de lazer. A forma como a sala de aula era constituída manteve-se inalterada nos últimos cinco séculos, ou até antes, o que, mais uma vez, reforça esse sentimento de estranheza diante dessa nova forma de se trabalhar.

O virtual representa um novo espaço peculiar, que possui características próprias, as quais possibilitam à educação utilizar ferramentas, formas, conteúdos e elementos que geram a nova forma de construção do conhecimento (Barros \&Gil, 2008).

\section{Reconhecimento, realização e expectativas profissionais}

Para Dejours (2011a), a análise psicodinâmica do trabalho mostra a importância do reconhecimento para o indivíduo, que é de natureza simbólica. Há o reconhecimento na forma de constatação, o que representa a contribuição individual para a organização do trabalho. Neste tipo de reconhecimento estão implícitas as imperfeições da organização do trabalho (ciência e técnica), assim como as falhas do trabalho prescrito e dos recursos que devem ser disponibilizados aos trabalhadores para fazer funcionarem os processos de trabalho. Ela implica a resistência da hierarquia superior, que não deseja ver a falha na estruturação do trabalho. Outro tipo de reconhecimento é no sentido de gratidão pela contribuição dos trabalhadores à organização do trabalho, o que é raro de acontecer. Pode-se acrescentar que há também a necessidade do reconhecimento social das atividades do indivíduo, que é a queixa da participante E1.

Segundo Gernet e Dejours (2011), o reconhecimento do trabalho contribui para a realização do "eu" no campo social. Graças ao trabalho, alguns sujeitos conseguem estabilizar sua identidade e diminuir o risco da doença mental e somática.

A maioria dos entrevistados declarou que o trabalho de EaD contribui para sua realização profissional. Eles se identificam com as atividades, acham que elas são desafiadoras e consideram bom poder trabalhar em casa em horários flexíveis.

Alguns professores sentem que suas expectativas foram atendidas e outros demonstram insatisfação quanto à falta de políticas e diretrizes claras. Pode-se entender que a EaD é fonte moderada de prazer e de sofrimento no trabalho.

EQ4 menciona que o diferencial entre o ensino a distância e o presencial não é o reconhecimento, pois são vistos da mesma forma, mas sim o fato de poder trabalhar em casa:

Pra mim, foi muito bom a questão de qualidade de vida, porque eu amo trabalhar em casa, eu gosto de ficar sentada não importa de ficar um tempão na frente do computador, mas o simples fato de estar em casa me descansa. Em termos de status e reconhecimento não alterou em nada.

E6 não se sentia reconhecida no desenvolvimento das atividades de $\mathrm{EaD}$ (atualmente, ela não exerce mais essa função). Ela afirma que os professores que só pertencem ao ensino presencial têm rejeição aos professores de EaD, porque acreditam que eles venderam seu trabalho, contribuíram para precarizá-lo. Esta afirmativa remete à importância que as pessoas dão ao reconhecimento social do seu trabalho pelos seus pares. Na medida em que isso não ocorre, há um sentimento de menos valia. Os professores presenciais que não lecionam na $\mathrm{EaD}$ não reconhecem esse trabalho como relevante, como se pode ver pela afirmativa a seguir: 
Eles têm uma rejeição porque, na verdade, o que se pensa realmente é que o professor presencial que está dando aula na $E A D$ vendeu o trabalho dele, precarizou o trabalho dele. $E$ é uma realidade, é uma rejeição que é real. Não é um mero preconceito, porque depois que você conhece como funciona você sabe que está numa mercantilização do ensino, é verdade.

E9 tem uma percepção exatamente oposta sobre a docência em EaD, porém, a partir de diferentes perspectivas. Ela se sente valorizada por exercer um tipo de trabalho inovador, sem se ater à opinião dos colegas, e sim à visão do futuro. Sente que está contribuindo para uma nova ordem social, na medida em que a EaD possibilita que mais pessoas possam estudar e a questão do reconhecimento pelo grupo depende do ponto de vista de quem avalia.

Eu acho que houve uma mudança cultural de reconhecer essa nova realidade, uma mudança de valor, sim, não valor financeiro, mas no sentido de reconhecer a diferença, de ter respeito pela diferença. Ver que é possivel fazer isso com seriedade, de estar contribuindo para uma nova ordem social.

A valorização, para os professores, depende do que é mais relevante para eles naquele momento. Ela tem uma vertente circunstancial, processual, decorrente do momento em que as pessoas estão vivendo.

A partir das diversas afirmativas dos professores pode-se concluir em relação ao reconhecimento profissional que eles não se sentem reconhecidos socialmente, nem financeiramente, apesar de a maioria deles se sentir realizada e identificar-se com a profissão. A situação de falta de reconhecimento pode gerar certo sofrimento e a busca de mecanismos de compensação, por exemplo: apesar de não serem reconhecidos, poderem trabalhar em casa, em horários de sua conveniência.

As subjetivações ocorrem em decorrência de sentimentos de compensações, como: não se sentir reconhecido, mas ter flexibilidade de tempo, mesmo que aparente, e trabalhar em casa. Ou seja, ao exercer uma atividade na qual controla o tempo de acordo com suas prioridades momentâneas e por estar em sua própria casa, na qual concilia seus diversos afazeres, o professor pode se sentir recompensado, por ser o gestor de seu próprio tempo. Outros percebem que seu trabalho possui uma dimensão social ampla, ao atingir uma população maior e contribuir para uma mudança social.

Para Chanlat (2011), além da questão da subjetividade, a questão identitária é igualmente importante para a pessoa, pois significa remetê-la às representações que ela tem de si mesma as quais alimentam-se de diversas fontes, como sexo, idade, corpo e origens familiares e sociais e se constroem por meio das relações que cada pessoa mantém com os outros. Na visão de Dejours (2011b), a realização de si mesmo depende de duas esferas: erótica e sexual e, no campo social, sendo que este último engloba o trabalho e o reconhecimento. Com relação ao amor, poucos gozam dele em sua plenitude. Sendo assim, é através do trabalho e do reconhecimento que as pessoas alcançam a estabilização ou o crescimento de sua identidade, escapando, por esta via, do risco de alienação e da doença mental. Para Dejours (2011b), essas questões são observadas principalmente nos jovens e idosos, diante do desemprego com o qual se deparam com mais frequência.

Os meios de trabalho e as organizações são sempre referências fortes na construção identitária. Ser professor, médico, padeiro, executivo ou engenheiro, por exemplo, reenvia elementos fortemente estruturantes para os indivíduos. As identidades profissionais estão sempre presentes em nossas vidas, porém em alguns momentos em situações de crise ou passando por profundas transformações. Como estamos em um sistema de produção capitalista que cria e se recria o tempo todo, essas crises muitas vezes são constantes na vida de algumas pessoas (Chanlat, 2011).

\section{Considerações Finais}

Os processos de trabalho mediados pela tecnologia no caso específico da EaD, influenciam os novos modos de subjetivaçãoou os novos modos de vida. Observa-se que ela está presente em todos os aspectos da vida das pessoas, mas que no caso da EaD não gera surpresa nem estranhamento quanto a sua utilização. Ela já está incorporada à vida pessoal, profissional e social das pessoas. O espaço e o tempo adquiriram outra dimensão, o que impacta com força a percepção e a cognição humana.

No trabalho virtual, os espaços e os tempos se misturam. O trabalhador virtual transforma seu espaço público em privado, e vice-versa. Constatou-se que ele ainda está aprendendo a viabilizar essa convivência. Há alguns que se disciplinam e colocam um limite ao tempo do trabalho e ao tempo de convívio social e familiar e há outros que ainda não conseguem fazê-lo, o que lhes causa um sentimento de mal estar.

Sugere-se que o sistema EaD que utiliza as TIC contemple o constante diálogo com os pesquisadores, estudiosos, professores e equipes de trabalho, pois é um campo novo, ambíguo, que possui críticas veementes de alguns autores e favoráveis de outros, mas que ainda está em construção, sujeito a erros de diversas naturezas. Os próprios pesquisados possuem visões bem diferentes sobre alguns aspectos.

As possibilidades que se vislumbram na educação com a utilização da internet são vastas, contemplando o ensino da graduação, pós-graduação, cursos de aperfeiçoamento, cursos modulares para desenvolvimento de habilidades específicas e outros. Em face dessa nova maneira de pensar e de perceber a realidade, é necessário que a Educação reflita sobre as atividades pedagógicas, os conteúdos, competências e habilidades a serem trabalhados e o tipo de comunicação, que é, predominantemente, escrita, ao invés de oral. A subjetividade do professor de EaD é modulada entre a flexibilidade diante do tempo e do espaço, mas concomitantemente a 
pressão de atender ao prazo definido pelo sistema, à perda dos laços sociais ou, no mínimo, à construção de uma nova maneira de relacionar-se. Podemos pensar que a EaD representa a sociedade de controle cunhada por Deleuze, onde os cerceamentos são decorrentes muito mais da tecnologia na sua dimensão virtual do que se vivenciava e ainda se experiencia na sociedade disciplinar em algumas instituições e atividades, estudada por Foucault. Pode-se observar isso em algumas afirmativas dos participantes, quando se queixam do aumento do volume de trabalho e do controle do sistema, pois as atividades não se restringem a um horário demarcado, mas se prolongam conforme a necessidade. Assim, entendemos que esses novos processos de trabalho desencadeiam novos processos de subjetivação, marcados por flexibilidades associadas a controles rígidos.

\section{Referências}

Barros, D. M. V. \& Gil, D. G. (2008). Cap. 5 - Espaço virtual como espacio educativo. Em S. F. Amaral, F. G. García, \& A. M. Rivilla (Orgs.), Aplicaciones educativas y nuevos lenguajes de las TIC. Campinas, SP: Graf. FE.

Belloni, M. L. (2003). Educação a Distância (3a ed.). Campinas, SP: Autores Associados (Coleção educação contemporânea).

Chanlat, J. F. (2011). O desafio social da gestão: a contribuição das ciências sociais. Em P. F. Bendassolli \& L. A. Soboll (Orgs.), Clínicas do trabalho: novas perspectivas para compreensão do trabalho na atualidade. São Paulo: Atlas.

Dejours, C. (1992). A loucura do trabalho: estudo de psicopatologia do trabalho (5a ed.). São Paulo: Cortez - Oboré.

Dejours, C. (2007). Prefácio. Em A. M. Mendes (Org.), Psicodinâmica do trabalho: teoria método e pesquisas (pp. 19-22). São Paulo: Casa do Psicólogo.

Dejours, C. (2011a). Addendum - Da psicopatologia à psicodinâmica do trabalho. EmS. Lancman \& L. Sznelwar (Orgs.), Christophe Dejours: Da psicopatologia à psicodinâmica do trabalho (3a. ed.) (pp. 57-123). Brasília: Paralelo 15/ Rio de Janeiro: Editora Fiocruz.
Dejours, C. (2011b). A saúde mental entre impulsos individuais e requisitos coletivos (sublimação e trabalho). Em S. Lancman \& L. Sznelwar (Orgs.), Christophe Dejours: Da psicopatologia à psicodinâmica do trabalho (3a. ed.) (pp. 409-430). Brasília: Paralelo 15/ Rio de Janeiro: Editora Fiocruz.

Dejours, C., Abdoucheli, E., \& Jayet, C. (2007). Psicodinâmica do Trabalho: contribuições da Escola Dejouriana à Análise da Relação Prazer, Sofrimento e Trabalho. São Paulo: Atlas.

Deleuze, G. (1992). Post-scriptum - Sobre as sociedades de controle. Conversações. Rio de Janeiro: Ed. 34.

França, A. C. L. F. (2007). Práticas de Recursos Humanos - PRH conceitos, ferramentas e procedimentos. São Paulo: Atlas.

Gernet, I. \& Dejours, C. (2011). Avaliação do trabalho e reconhecimento. Em Bendassolli, P. F. \& Soboll, L. A. P. (Orgs.), Clínicas do trabalho - novas perspectivas para compreensão do trabalho na atualidade. São Paulo: Atlas.

Mill, D. \& Fidalgo, F. (2009). Uso dos tempos e espaços do trabalhador da educação a distância virtual: produção e reprodução no trabalho da Idade Mídia. Cadernos de Educação, (32), 285-318.

Ponte, J. P. (2000). Tecnologias de informação e comunicação na formação de professores: Que desafios? Revista Iberoamericana de Educación, 24, 63-90.

Rose, N. (2001). "Inventando nossos eus". Em T. T. Silva (Org.), Nunca fomos humanos (pp. 137-204). Belo Horizonte: Autêntica.

Schwartz, Y. (2011). Manifesto por um ergoengajamento. In: Bendassoli P. F. \& Soboll, L. A. P. (orgs.) Clínicas do trabalho novas perspectivas para compreensão do trabalho na atualidade. São Paulo: Atlas.

\section{Sobre os autores}

Maria Antonieta Mendes da Luz (mariaantonietaluz@gmail.com)

Docente da Pontifícia Universidade Católica de Minas Gerais - PUC Minas; doutora pela PUC Minas.

João Leite Ferreira Neto (jleite.bhe@terra.com.br)

Docente da Pontifícia Universidade Católica de Minas Gerais - PUC Minas, doutor pela PUC - SP, bolsista de produtividade do CNPq.

Este artigo derivou-se da tese de doutorado da primeira autora com orientação do segundo autor. 